\title{
Cooperative learning in peer teaching: A case study in an EFL context
}

\author{
Dyah Sunggingwati \\ English Department, Teacher Training Faculty, Mulawarman University, Samarinda, East Kalimantan, Indonesia
}

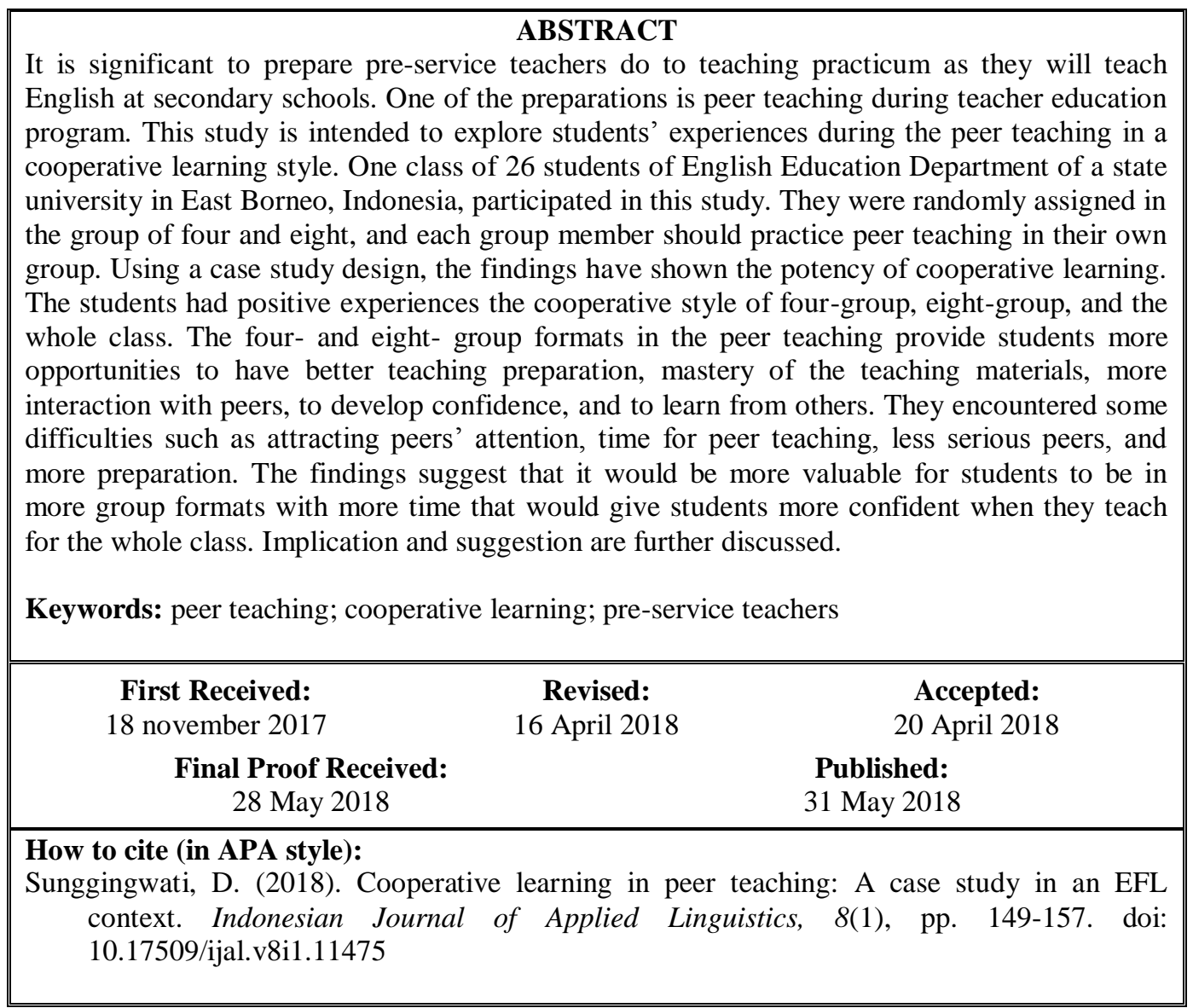

\section{INTRODUCTION}

When teachers teach in the classroom, students may see it as common and regular actions that anyone could accomplish it. Loughran (2013) points out that teaching is often perceived as passive activities as it seems assomething direct and uncomplicated. This might come from the sense that teaching is a series of teaching action done in the classroom to deliver the materials or information from teachers to students. However, "Teaching then is not bound by a script or set of routines but depends on a teacher making informed decisions about practice. From this perspective, teaching is dynamic and demanding because it must be responsive to the varied learning demands inherent in the situation" (Loughran, 2013, p.120). This implies that in fact teaching is not as simple as it is perceived in common but vigorous and tends to be complex. $\mathrm{Xu}$ and Conally (2009) have accentuated that "[w]hen a teacher responds to a student or designs a particular lesson, their actions and plans are based on the totality of their experience" (p.221).

Regarding teacher preparation, Cochran-Smith and Villegas' review (2015) which was mostly conducted in US context found that recent research on teacher preparation concerns on two questions; the policy and the learning question. The policy question deals with the impact of policies to accountability and effectiveness of the teacher preparation, and how the institutions correspond the policies. The learning question links with the views that "teaching is a complex intellectual

\footnotetext{
* Corresponding author:

Email: sunggingwati@gmail.com
} 
work and evolving views of learning to teach as ongoing over the professional lifespan" (p.9). This underlines that teaching is closely related with intelligence, continuous action, and is long-life learning.

Moreover, teachers earn knowledge from formal and informal educational experiences. Most formal educational experience is obtained from teacher education program that has impact on what teachers' beliefs which they might practice in their teaching (Borg, 2011). In particular, the lack of knowledge in English will impede the teaching preparation in terms of the learning objectives (Barnes, 2002; Cullen 1994; Edge, 1988). Thus, this educational experience signifies what the teachers would do with their students in the classroom.

Meanwhile, in the context where this study was conducted, Microteaching is one of the requirement courses that pre-service teachers of English department should enroll. This is accomplished before they have a teaching practicum program at secondary level schools. In this course, they learn how to teach through peer teaching and they have to review previous materials such as learning theories, teaching methodology, and classroom management. They also reexamine theories of ELT, create lesson plans, and do assessment.

One vital activity the students have to fulfill in the Microteaching course is peer teaching conducted at the end of the course period. Each student should teach, taking the role as a teacher, and their classmates become the students. The peer teaching focuses on the features of teaching attained from the faculty comprises preparation before teaching, main activity, teaching strategy, the use of media, students participation, assessment, the use of language, and closing. The evaluation used in this study is similar to the one that applies in the teaching practicum at schools. Using similar evaluation would provide students more awareness of the teaching features that they have to alert to.

Concerning to the educational experiences that influence what the teachers do in the classroom, this study is intended to explore experiences in peer teaching for pre-service teachers working in group which is closely linked with the cooperative learning approach which will be discussed in the next section.

\section{Peer teaching}

Peer teaching is considered as an effective way of learning. It refers to teaching that takes place which one student teaches one or more fellow students within the same peer (Gregory, Walker, Mclaughlin, \& Peets, 2011; Mackinnon, Haque, \& Stark, 2009). Research has indicated that peer teaching is an effective approach to stimulate and improve learning in the classrooms (Goodlad \& Hirst, 1989; Rubin \& Herbert, 1998; Boud, Cohen \& Simpson, 2001; Gordon, 2005; Liu \& Devitt, 2014).

Literature about collaborative teaching suggests that there is a necessity to rethink student teaching and to have alternative models of field experience (Bullough et al., 2002). In particular, given the complexity of teaching, there is need for models that enhance teachers "collaborative problem-solving capacity" (Buchberger, Campos, Kallos, \& Stephenson, 2000, p. 49). As Howey and Zimpher (1999) argue, "Most fundamental to the improvement of teacher education is addressing how all teachers are prepared to work with one another' ( $p$. 294). This echoes that preparation to work collaboratively in the teacher education program should be well-planned.

Meanwhile, numerous studies have demonstrated the effectiveness of Cooperative Learning methods for the promotion of student learning and social relations (Abrami et al., 1995; Asakawa, Kanamaru, Plaza, \& Shimarazu, 2016; Astuti \& Lammers, 2017; Cohen, 1994; DelliCarpini, 2008; Gillies \& Boyle, 2011; Johnson \& Johnson,1999; McAlister, 2012; Veenman, Benthum, Bootsma, Dieren, \& Kemp, 2002). Literature of cooperative learning (Johnson \& Johnson, 1994; Johnson, Johnson, \& Smith; 2007) indicate that there are some benefits of this learning type. Within cooperative situations, CL offers some advantages such as deeper understanding of learned material, lower levels of anxiety, and stress, greater ability to view situations from others' perspectives, more positive and supportive relationships with peers, more positive attitudes towards subject areas, and higher self-esteem.

Experts underline that teachers must understand the nature of cooperation and the essential components of a well-structured cooperative lesson in order to effectively use CL (Johnson \& Johnson, 1994; Johnson, Johnson, \& Smith, 2007). Teachers with real expertise in the use of CL include five essential components in their instructional activities: (1) positive interdependence, (2) individual accountability, (3) faceto-face promotion interaction, (4) social skills and (5) group processing. Therefore, simply placing students in groups and telling them to work together does not in and of itself produce a cooperative effort. Further, Slavin (1995) emphasized that in CL classrooms, the students are expected to help, discuss and argue with each other; assess each other's current knowledge. When properly organized, students in CL groups make sure that everyone in the group has mastered the concepts being taught.

In her research review of CL development, Gillies (2014) suggests at least three key factors for effective and successful cooperative learning including group structure, composition and task, and teachers' role. Small groups structure of 3-4 members will result higher learning outcome than that of 5-7 members. Activities in the classroom that demonstrate discoverybased tasks have proved more interactions as the students' exchange ideas and information. Teacher's role is significant to create classroom atmosphere that allows and provides students more interactions.

Research on CL with student teachers has been conducted over a decade and most of it indicated its benefits. Veenman et al. (2002) conducted a study related to the implementation effects of a course on CL 
for student teachers. CL has been found to be beneficial for not only the student teachers themselves but also for those who want to use CL in their classes in the future. Although the student teachers in this study recognized that the development of their skills in using CL had just begun, they appeared to be very motivated to further develop this newly acquired competence.

The need to be involved in the effective model of CL is essential. DelliCarpini (2008) conducted a study of a TESOL teacher educator took reflective action in an ESL methods class with the goal of increasing preservice and in-service teachers' use of CL activities in their own ESL classrooms. Despite the benefits and the prevalence of the topic in teacher educational contexts, CL was not as widespread as would be expected. Teaching practices were influenced by teachers' prior experiences and beliefs. If pre-service teachers were not exposed to effective models of $\mathrm{CL}$ in their teacher education programs it might be unrealistic to expect them to engage in CL in their own classrooms. This indicates that the pre-service teachers need to be engaged in CL experience.

More benefits of CL were also investigated through teachers' perceptions. Gillies and Boyle (2010) reported the teachers' views regarding the $\mathrm{CL}$ implementation. The data were gathered from interviews of the 10 middle year teachers who employed cooperative learning in the five different schools in Brisbane, Australia. The results showed that all the teachers had positive perceptions regarding the CL experiences. All their students were well responded towards small groups that helped them to have better lesson plan structure and management. The teachers were more confident with some considerations such as well-planned of cooperative learning and readiness of the students to work in group.

McAlister' (2012) study explored student teachers experience in a modeled CL in a Course of Pedagogy and Curriculum at a Scottish University. The results indicated the benefit as well as the challenges of the CL implementation. Most student teachers were able to transfer what they have learned in the training to the classroom. They were confident in using the CL and able to recognize interaction occurred during the implementation. The researcher found that behavior of trying to implement many $\mathrm{CL}$ in short period of time, some of the student teachers were unconfident and lack of interest of the CL by their students and the schools.

Research by Asakawa et al. (2016) showed that guidance is necessary in CL. The authors conducted a follow-up study with nine graders at private secondary school in Japan who had learned CL since 2011. Questionnaires related to the list of expressions were distributed after 22 months of list implementation to see their benefits. The findings revealed that the students generally found that the list was beneficial to assist communication with their classmates. They suggested that guidance and support were required to have effective CL.
In Indonesian context, a recent study by Astuti and Lammers (2017) investigated the role of individual accountability as one aspect of CL with two teachers from middle and high schools and their students. Using a case study, the findings revealed that individual accountability allowed peer interaction, comprehensive input and output, and opportunities of task sharing among the students.

Although research generally has revealed positive effects of CL, CL can also have some drawbacks. Johnson and Johnson (1994) identify that group members sometimes seek a free ride on others' work by leaving completion of the group task to the others. Students who get stuck doing all the work sometimes will decrease their efforts. Along a different line, pressure to conform may suppress individual efforts. Group work can also break down as a result of divisive conflicts and power struggles (Johnson \& Johnson, 1994). CL can also pose a serious instructional dilemma when it creates situations in which students who are academically low achieving or social isolates become excluded from the interactions. CL, by itself, does not provide access to equitable relations for all students. Cohen (1994) suggested to train students explicitly in cooperative skills by giving them feedback on their cooperative behaviors and asking them to reflect on how the group members worked together, or by structuring positive interdependence and individual accountability.

Time was identified as one of the challenges in the CL implementation. Ning's (2013) study explored the effect of CL on the development of social skills in English as a foreign language (EFL) tertiary students in Chinese context. Using a quasi-experimental design, the findings indicated that CL were more effective than the traditional instruction to improve social skills of the students. Equal participation and accountability emerged and students' self-confidence improved although the difference was not significant. The author indicated that initiative in socialization, being positive, acceptance and empathy, and conflict management were not apparent due to limited time of intervention.

Bearing in mind the importance of educational experience, Farrell and Jacobs (2016) discussed their expertise in teacher reflection with CL literature. They affirm that reflective practice done by the teachers is a cooperative-social activity because supportive environment where they share and talk could be achieved when the teachers are in the teacher reflection group. They assert that teachers need to be in the teaching methodology they practice in the classroom, therefore when teachers have experienced effective CL for themselves, they would be likely to implement what they achieve in the CL. Farrell and Jacobs claim that "their belief in the power of peer learning grows" (p. 7) that would force them to anticipate the challenges they might encounter in the implementation of CL in their teaching. This denotes that teachers need to be involved in the teaching method they teach, and being experience in the teaching method they teach would offer better comprehension related to its realization. 
Previous studies have demonstrated the potency of CL, however, there is limited research that has informed the obstacles how to perform the cooperative learning with considering the circumstance in chorus. Therefore, this present study addresses the students' experiences during the peer teaching focusing on the following formulated questions to guide this study:

a) What are the benefits of being in a cooperative learning style in peer teaching?

b) What challenges do the students encounter during peer teaching?

\section{METHOD}

As context is crucial, a case study approach was employed to examine the particular location and program of teaching. Using this design allowed the researcher to investigate phenomena within the real-life context to provide richer and more varied set of circumstances to investigate (Yin, 2003).

This study involved one class consisting of 26 students of English Education Department of a state university in East Borneo, Indonesia. They were in the 6th semester who enrolled a course of Microteaching as a preparation for teaching practice program at secondary school level when they are in the 7 th semester.

In this study, CL style was implemented in the peer teaching. The students had to attend to three different types of grouping; group of four, group of eight, and whole class. The students were randomly assigned in the group of four, therefore there are six groups participated in this study. Each group member had to practice peer teaching in their own group for about 10-15 minutes. After each member had presented, oral feedback from group members would be given. In addition, personal report of experience during peer teaching was accomplished.

After completing the group of four, the students would form a group of eight. This formation was randomly matched from the previous group of four. Similar in the four-group member, the students in the eight- group member should provide oral feedback and self-report after the peer teaching for 10-15 minutes.

As the final grouping, the students had peer teaching for the whole class after participating in the group of four and eight. This was completed for 30 minutes for each student.

The data of this study were mainly gathered from self-report and observations during peer teaching. The self-report of each student from two different forms of grouping would focus on the students' experience during their peer teaching as well as delivering oral feedback from the group members. Observations were completed to gain comprehensive understanding of what occurred during the peer teaching in the group of four, eight, and the whole class.

The analysis of students' self-reports began by reading all information to get broader depiction of the data. Next, reflection on the experience during peer teaching and identification what the students have learned from the peer teaching in four-group and eightgroup practice as well as challenges was analyzed. Initial coding for what the students did during the peer teaching in different form of groups was employed to identify which data were relevant to the focus of this study. The data were then selected and reduced to the data that concentrated on the students experienced during the peer teaching. Similar codes were combined to provide similar patterns and themes. This allowed the data to be managed for further analysis. Next, initial analysis and conclusions were drawn.

The data of observations which focused on how the students conducted the peer teaching and activities during the peer teaching were in the form of field notes. Following this, coding for similar information from the reports was undertaken. Similar codes of information were used to develop small number of themes which would then be used to build main themes.

\section{FINDINGS AND DISCUSSION}

The findings from the self-report shows that generally the students had positive experience from being in the cooperative style of 4-group, 8-group and the whole class. The four- and eight- group formats in the peer teaching have provided students more opportunities to have better in teaching preparation, mastery of the teaching materials, more interaction with peers, to develop confidence, and to learn from others. Additionally, some students indicated unenthusiastic responses.

\section{Teaching Preparation}

More than $50 \%$ of the students reported that the use of cooperative learning style during the course of Microteaching has offered them with better teaching preparation as one of the students wrote:

Being in a group of 4 and then in the group of 8 to teach the whole class is actually a good way for students to improve their teaching preparation. I think in the group of $4 \mathrm{I}$ was less serious than in the group of 8 but I was very serious in peer teaching for the whole class but a bit nervous. (S-10)

The student's report indicated that being in a bigger group progressively has given the students more time to prepare their teaching and more thoughtful although felt slightly nervous for teaching the whole class. Further, they felt they could have more space to move and monitor their peers' activities as one of them reported:

I felt more comfortable in bigger class because I have practiced at home and in the previous groups of 4 and 8 . I could have more gesture to move around the students and handle my tension by stopping for a while to take deep breath and continued. I speak louder and that make me able to draw students' attention although it made my voice lose (S-15). 
The quote shows that more effort such as preparation and louder voice needed to be put in when the students had to teach for the whole class. Teaching a whole class was more relaxed for her as she had better classroom management. Rehearsal at home assisted her to be more confident in teaching.

\section{More mastery of the teaching materials}

The reports also specified that the students tried to be competent to the material they taught as they had chances to teach the same material in the bigger groups. This could be seen in the following reports:

In a 4-group, I think I was not ready to teach the lesson in front of my friends, therefore when teaching in a group of 8 , I wanted to master the topic I taught. I had to learn more the material I was going to teach and tried to reduce my tension. (S-8).

The statement above shows that the student realized that he did not really master the topic he had to teach in the group of 4 therefore he tried dissimilar activities in teaching his peers in the group of 8 and the whole class. In addition, the students also had more occasions to revise their lesson plan better and hence it improved their mastery of the materials they taught as one student informed as follows:

When I taught in the group of four I felt that I lacked of preparation in terms of the topic and distribution of exercise to my students. In the group of eight I felt that my material delivery was more structural because I had revised my lesson plan. Finally, in the whole group I was better preparation mentally and physically, revised lesson plan, better time management, made-test exercise and more confident when teaching. (S-24).

The report shows that the process of being in the group contributed the students to be better in their teaching since they have learned from the mistakes in the groups with better topic mastery. This implied that allowing the students to revise their lesson plans and give time to observe their peers simultaneously could broaden their knowledge and reflect their mistakes or weaknesses.

\section{More interaction with peers}

The students are able to have more interaction with their peers as they have feedback from them to improve their teaching performance as one student reported as follows:

After teaching in front of my friends, I found some good changes. I am not confused to deliver the material and feel more confident. During the teaching, I was able to question my friends, attract their attention to focus and to communicate well. I think this is because of the exercise of teaching in the groups so I feel positive improvement. (S-7).

The statement above reveals that the student had better peer teaching presentation for the whole class as he was able to interact with his peers and felt comfortable in his teaching. In addition, the finding also exhibits that he gained some benefits from the groups such as communication skill.

\section{Developing confidence}

Most students' statements point out that the groups have provided them more chances to develop their confidence in teaching:

I think the method used in the course is quite good. First we are teaching in group of 4 and next we are teaching in group of 8 and the last we are teaching with the whole class. In the group of 4 , I felt nervous and was not confident. I couldn't speak clearly and the way I explained the topic was quite bad. My students got difficulty to get the points. My friends gave me suggestion to read again and prepare before teaching. In group of 8 , I presented the material better than in the group of 4 , I felt more confident and calm. The second time I presented the same material so I understand more and explained well. In the whole class it was better than I expected because we already teach the same material as in the group of 4 and 8 . My nervous was gone and I was more confidence, and I thought I did it better. (S13).

The statement above shows that the student developed her confidence as she was gradually in the bigger group. She reduced her anxiety that enabled her to speak clearly, to have better mastery and preparation of the materials, and to feel confident. In addition, the feedback from the group members assisted them to enhance their teaching performance as one student reported as follows:

Practice teaching at the Microteaching course was not my first experience of teaching but I think it makes me little bit nervous. For group of 4 , I made mistake with explanation before I gave the materials. I was so nervous because I was the first who taught. When I started I forgot to bring my power point to explain my materials. So I just explained my way and of course I gave my students the exercise. I really need this practice to handle my nervous. For group of 8 I was nervous but less than in the group of 4 . It was because my friends helped me to speak difficult words. For the whole group, I was a little nervous although I prepared my materials and exercises well. At first my hands were shaking, and I forgot what I should say but in the middle of the teaching, I really enjoyed it until the end. So the group was really good for preparing teaching. (S12).

So the peers worked cooperatively to help their teacher be better in their teaching performance and to lessen anxiety. This shows that that the role of the group to support peer was significant to the successful of their teaching.

Learned from others about teaching methods

Peer teaching also has offered the students to learn from others as one student wrote as follows: 
Practicing teaching from group of 4 and 8 to the whole class is that I can see the teaching style from my friends. I could choose and take examples of what method that makes teaching more interesting and what not. (S-21)

The student was able to observe the others to adopt the teaching style to make their own teaching was more interesting. They could reflect and used their reflection to improve their teaching. Furthermore, they also adapted not only the teaching style but also how to make the class more interactive.

I was not nervous in the group of 4 or 8 because the students were my friends however, it made me less serious in teaching because too much joking with them. When I taught at the whole class I was quite confident because I did rehearsal a lot at home, I also observed my friends how they taught previously. I learned how to make pleased class by making some jokes, how to apply teaching media using power point to lessen boredom even though I still felt nervous for teaching the whole class for the first time. (S-20)

Teaching the whole class made the students become more serious than teaching the peers in groups as too much jokes with the members of the group. However, students could still learn from others in terms of how to make jokes and the use of media.

In addition to the positive responses, the selfreport has pointed out that the advantages and difficulties of the grouping in the cooperative learning style have provided the students some insight they might have in the teaching practicum at schools.

\section{Unenthusiastic responses}

Among those positive responses towards cooperative learning style, two students also indicated some unenthusiastic responses. One student wrote that she needed to put more effort to teach the whole class rather than in groups.

I think explaining the materials is easier than attracting students' attention. Using games could make the lesson is more interesting but I feel awkward to do that. I think I need to do better. Attracting students' attention in the group of 4 and 8 was easier than in the whole class, my friends' attention was spread up. (S-16).

The statement signifies that drawing peers' attention to focus on what the teacher taught was harder for the whole class than in the group of four and eight. Furthermore, the students were still nervous in teaching for the groups and the whole class as one student reported:

When I had teaching practice in the group of 4 I felt a little bit nervous, but only for a moment in the beginning. It was still enjoyable because the students were my close friends. For the second practice with eight people, it was just like with four people. I felt little bit nervous when I started to explain my material my nervousness starting to fade. It was a big different when I had to teach I in front of the whole class. I felt nervous, my hands were shaking and cold, it was like all my teaching experience in group of four and eight. It did not give any help when I stood in front of many people. Fortunately, I had such very good classmates who want to cooperate with me. (S-23).

This report reveals that the student experienced similar feeling of anxiety in the three different grouping meaning that the group of four and eight did not help her to reduce nervous when she taught for the whole class, however, the cooperative classmates helped her to handle her tense.

The observation, as supported data, was conducted in each stage of grouping to provide better understanding from the main data of self-reports. There were six groups of group of four. Some students made jokes and laugher among themselves in the four groups although this was the first time for students to practice teaching, while the other two were quiet and looked serious when one of their friends was teaching. In the pre-teaching session, the students seemed serious and tense but they became less formal when in the middle of the lesson. In the last stage of their teaching, some were able to draw some conclusion what had been taught while others immediately end their teaching. Because of limited time given for peer teaching, the students used their laptop for teaching media while others distributed handout to their peers. The peers asked questions and responded the teacher explanation. I also noticed that some still relied on their lesson plan to see the sequence of teaching activities. The use of English as a medium of instruction was fully implemented.

In the group of eight the students did similarly what was occurred in the group of four. Two groups of four formed one group of eight. In this group, more interaction between the teacher and the group members occurred that created much noise. Thus, this required the students who taught in front of their peers made their voice louder.

For teaching the whole class which lasted for 30 minutes, the students seemed to have better preparation, media, and teaching strategy. Their peers could pay fully attention because only one student as their teacher taught their class. The peers were able to respond the teacher questions and instructions during the teaching and learning process that generate positive responses. These enabled the class to maintain student-teacher interaction in comfortable atmosphere.

The key findings generated from the self-reports have exhibited that the students improved their teaching preparation and became to more master the teaching materials as they had more time to prepare and ponder the teaching materials.

During the teaching and learning process in the CL style, the findings from the self-report and observation have revealed that interaction with the peers also occurred contentedly although in some groups seemed less thoughtful in the form of group of four. This finding is in line with the previous studies (Veenman et.al, 2002; DelliCarpini, 2008) that more interaction was achieved in the CL. This implied that there is 
positive interdependence in which the students interact and respond to help each other that allow them be better in their teaching. They are expected to discuss what they are learning in this case their teaching performance and how to improve it as well as to provide each other with help, assistance, support and encouragement (Johnson \& Johnson, 1994; Slavin 1995).

As the students were in the group of eight, they became more confident and were able to take lessons from others such as adapting the teaching methods, the use of media and how to make the class became vivid. This result supports previous studies by Gillies and Boyle (2010) and McAlister (2012) showing that confidence could be improved using $\mathrm{CL}$.

In addition, the peer responses during the teaching process has allowed the students to have positive experience. Assistance, discussion as well as arguments from peers in a small group allow the students to support each other. Johnson and Johnson (1994) emphasize that using a small group in cooperative learning that students work together will maximize their own and each other's learning. Thus, as Slavin (1995) underline that this will provide opportunities for students to learn and to fill the gap of other's current knowledge and understanding.

Being in a group of four into a group of eight has given more opportunities for students to reflect about themselves. The students became aware things they needed to improve for their teaching. Oral feedback given after teaching from their peers has contributed to their reflection that they hence realized what needed to be improved in their teaching. This teaching reflection has been highlighted as a critical stage for teacher experiences (Farrell \& Jacobs, 2016).

The students in this study did peer teaching throught explicit cooperative skills, providing feedback for their peers, and asking them to reflect on how the group members worked together. These have resulted positive interdependence and individual accountability (Astuti \& Lammers, 2017; Cohen, 1994).

As a result of having involved in the group of four and eight, the students had more time to organize their teaching plans, methods, and media that allowed them to become skillful in their teaching materials (Ning, 2013). Consequently, they had more chances to develop their confidence in their teaching performance. This implied that group processing is present as the members of the group discuss their progress towards the achievement of their teaching and the maintenance of effective working relations from group of four until their teaching performance for the whole class (Johnson \& Johnson, 1994).

Within cooperative situations, individuals seek outcomes that are beneficial to themselves and beneficial to all other group members. Cooperative learning is the instructional use of small groups so that students work together to maximize their own and each other's learning (Gillies, 2014; Johnson \& Johnson 1994, Slavin, 1995).
The findings yielded in this study have provided convincing evidence that CL style particularly in the peer teaching has offered advantages for students to increase their confidence, strengthen their mastery of the materials they are teaching, and reflection towards their own teaching.

The peer's feedback has contributed to the improvement of students teaching performance as well as student-teacher interaction. The peer's responses in the teaching and learning process moderately have diminished students' tension in teaching. The expected goal of cooperative learning seems to have been achieved in this study as the students had positive understanding towards cooperative learning style implemented in this study. These results were consistent with previous studies which have shown that CL is valuable for students (Astuti \& Lammers, 2017; Asakawa et.al., 2016; DelliCarpini, 2008; Farrell \& Jacobs, 2016; Gillies \& Boyle, 2010; McAlister, 2012; Ning, 2013; Veenman, et. al., 2002).

\section{CONCLUSION}

In general, this study has resulted more positive outcome of cooperative learning style. There needs more effort such as preparation and louder voice should be put in when the students have to teach for the whole class. However, they were more relaxed as they were able to have more manageable classroom. In addition to this, teaching rehearsal at home assisted them to be more confident in teaching.

Attracting peers' attention to focus on what the teacher teaches was harder for the whole class than in the group of four and eight. The students required more time given in the peer teaching in the groups. Furthermore, some students were nervous in teaching for the groups and the whole class.

The findings from the observation revealed that some students were rated as very good in teaching strategy as the students' participation was much better than those who had teaching strategy considered as good one. Only in closing sometimes the students sometimes forgot to ask their peers to draw a conclusion after the time was over. In addition, the peers were less serious in the group of four and this might happen because of close friends. However, as they were in the group of eight and in the whole class they became more concentrated.

This study advances our understanding the benefits and difficulties encountered by the students of the implementation of $\mathrm{CL}$ in peer teaching. $\mathrm{CL}$ in peer teaching has given students advantages specially to lessen anxiety in the peer teaching. Therefore, it would be more valuable for students to be in more group formats with more time that would bestow students more confident when they teach for the whole class. Oral feedback from group members were completed in this study but less attention given to this feature, hence it is necessary to have written feedback from peers as part of aspect to be considered as a teaching reflection. 
The results of this study bring some implication particularly for teacher education that allowing the teachers to be experience in their teaching methods and do reflection would provide broader understanding towards their teaching and themselves.

Since the data in this study were mainly gathered from what the students reported and observations future research with similar interest might include interviews to achieve deeper understanding the participants' insight during their experience in the peer teaching with cooperative learning style.

\section{REFERENCES}

Abrami, P. C., Chambers, B., Poulsen, C., De Simone, C., d'Apollonia, S., \& Howden, J. (1995). Classroom connections: Understanding and using cooperative learning. Toronto: Harcourt Brace \& Company.

Astuti, P. \& Lammers, J.C. (2017) Individual accountability in cooperative learning: More opportunities to produce spoken English. Indonesian Journal of Applied Linguistics, 7(1), 215-228. doi: dx.doi.org/10.17509/ijal.v7i1.6878

Asakawa, M., Kanamaru, A., Plaza, T., Shimarazu, C. (2016). Useful expressions for implementing cooperative learning in English. TESL-EJ, 19(4), $1-16$

Barnes, A. (2002). Maintaining language skills in the initial training of foreign language teachers. The Language Learning Journal, 14, 58-64.

Borg, S. (2011). The impact of in-service teacher education on language teachers' beliefs. System, 39, 370-380.

Boud, D., Cohen, R., \& Simpson, J. (2001). Peer learning in higher education. London: Kogan Page.

Buchberger, F., Campos, B. P., Kallos, D., \& Stephenson (Eds.). (2000). Green paper on teacher education in Europe: High quality teacher education for high quality education and training. Umea, Sweden: Thematic Network on Teacher Education in Europe.

Bullough, R. V., Jr., Young, J., Erickson, L., Birrell, J. R., Clark, D. C., Egan, M. W., ... Smith, G. (2002). Rethinking field experiences: Partnership teaching vs. single-placement teaching. The Journal of Teacher Education, 53(1), 68-80.

Cochran-Smith, M. \& Villegas, A.M. (2015). Studying teacher preparation: The questions that drive research. European Educational Research Journal, 14(5), 1-16. doi: 10.1177/1474904115590211

Cohen, E. G. (1994). Restructuring the classroom: Conditions for productive small groups. Review of Educational Research, 64(1), 1-35.

Cullen, R. (1994). Incorporating a language improvement component in teacher training programmes. ELT Journal, 48(2), 24-38.
DelliCarpini, M. (2008). Enhancing cooperative learning in TESOL teacher education. ELT Journal, 63(1), 42-50.

Edge, J. (1988). Applying linguistics in English language teacher training for speakers of other languages. ELT Journal 42(1), 9-13.

Farrell, T.S.C. \& Jacobs, G.M. (2016). Practicing what we preach: Teacher reflection groups on cooperative learning. TESL-EJ, 19(4), 1-9.

Gillies, R. (2014). Cooperative learning: Developments in research. International Journal of Educational Psychology, 3(2), 125-140. doi: 10.447/ijep.2014.08

Gillies, R. \& Boyle, M. (2011) Teachers' reflections of cooperative learning (CL): A two-year follow-up. Teaching Education, 22(1), 63-78. doi: 10.1080/10476210.2010.538045

Goodlad, S., \& Hirst, B. (1989). Peer tutoring: A guide to learning by teaching. London: Kogan Page.

Gordon, E. E. (2005). Peer tutoring: A teacher's resource guide. Lanham, MD: Scarecrow Education.

Gregory, A., Walker, I., Mclaughlin, K. \& Peets, A.D. (2011). Both preparing to teach and teaching positively impact learning outcomes for peer teachers. Med Teach, 33, 417-422.

Howey, K. R., \& Zimpher, N. L. (1999). Pervasive problems and issues in teacher education. In G. A. Griffin (Ed.), The education of teachers: Ninetyeighth yearbook of national society for the study of education (pp. 279-305). Chicago: University of Chicago Press.

Johnson, D. W., \& Johnson, R. T. (1994). Learning together and alone: Cooperative, competitive, and individualistic learning. Boston: Allyn and Bacon.

Johnson, D. W. \& Johnson, R. T. (1999). Making cooperative learning work. Theory into Practice, 38(2), 67-73.

Johnson, D. W., Johnson, R. T., Smith, K. (2007). The state of cooperative learning in postsecondary and professional settings. Educational Psychology Review, 19, 15-29.

Liu, W. \& Devitt, A. (2014). Using reciprocal teaching to develop learner autonomy: An action research project with a beginners' Chinese class. CercleS, 4(2), 489-505.

Loughran, J. (2013). Pedagogy: Making sense of the complex relationship of teaching and learning. Curriculum Inquiry, 43(1), 118-141.

Mackinnon, R., Haque, A., \& Stark, P. (2009). Peer teaching: By student for student. A student-led initiative. The Clinical Teacher, 6(4), 245-248.

McAlister, C.M. (2012). Modeling in initial teacher education (ITE): Reflections on the engagement of student teachers with cooperative learning in ITE. Teacher Development, 16(3), 303-320.

Ning, H. (2013). The impact of cooperative learning on English as a foreign language tertiary learners' social skills. Social Behavior and Personality, 4(4), 557-568. 
Rubin, J., \& Herbert, M. (1998). Peer teaching: Model for active learning. College Teaching, 48(1), 2630 .

Slavin, R. E. (1995). Cooperative learning: Theory, research, and practice. Boston: Allyn and Bacon.

Veenman, S., Benthum, N., Bootsma, D., Dieren, J., Kemp, N. (2002). Cooperative learning and teacher education. Teaching and Teacher Education, 18, 87-103.
Xu, S. \& Connelly, M. (2009). Narrative inquiry for teacher education and development: focus on English as a foreign language in China. Teaching and Teacher Education, 25, 219-227.

Yin, R. K. (2003). Applications of case study research (3rd ed.). Thousand Oaks, CA: Sage. 